\title{
Valdelomar, viajero
}

\author{
Por Estuardo NúñezZ
}

Valdelomar representa, con sus preclaros méritos y aún con sus limitaciones, esa etapa de la literatura continental que señala con el tramonto del Modernismo, el advenimiento de nuevas corrientes que forman la producción literaria actual. Su extraordinaria capacidad creadora hace que Valdelomar inscriba su nombre en alto sitial, no obstante las imperfecciones y contingencias de una obra en gran parte fragmentaria y destinada al periodismo, desarrollada en sólo 31 años de vida, o sea en sus escasos 15 años útiles de creación. Pocos escritores del Perú, de América o del mundo han podido realizar en lapso semejante, una obra literaria tan estimable en cantidad y calidad. Pensemos por un momento en looque habialpioducidd disdicha edad Palma (en 1864). González Prada (en 1879) o José Santos Chocano (en 1902). El primero comenzaba a escribir, un tanto inseguro, algunas tradiciones y sólo había publicado una colección de poemas; el segundo no había escrito ninguno de sus libros salvo Minúsculas, todavía inédito, y el tercero no había ofrecido aún a la publicidad su primer libro definitivo: Alma América, aparecido sólo en 1906. Esta comparación de fechas no es, sin embargo, un recurso para regatear el mérito a nadie en beneficio de alguien, pero sirve de referencia para ayudar a la imaginación a reconstruir ei concepto de la valoración de un autor prematuramente desaparecido, como Valdelomar.

Trayectoria

Valdelomar tuvo el reiterado presentimiento de su pronto y precoz final. Por ello se justifica su prisa y su infatigable laborio- 
sidad y hasta su despreocupación por pulir sus relatos. A cambio de la limitación del tiempo, parece haber mediado como compensación, la multiplicidad de su inquietud, su fervor en la producción y su febril versatilidad. Espigó en casi todos los campos de la actividad intelectual. Desde las aulas escolares, como "guadalupano" insigne, ya esgrime la pluma o el pincel antes de los 15 años, para aparecer luego como dibujante de excelente factura, al lado de Málaga Grenet, en Monos y Monadas y antes en Aplausos y Silbidos. Hasta agosto de 1913 en que Valdelomar emprende el viaje a Italia, había ya colaborado en las revistas más estimables de Lima: Actualidades, Letras, Gil Blas, Ilustración Peruana, Variedades y en un semanario de modestísima factura pero de inolvidable inquietud, Balnearios, que dirigía Alfredo Muñoz, en Barranco. Su colaboración se prodigaba en poesías, en crónicas como las que tituló "Con la argelina al viento" -en que vuelca su experiencia de soldado durante la movilización de 1910, junto con la de otros inielectuales- y hasta en algún ensayo de novela como "La ciudad de los tísicos", desconcertante trama dannunziana, con insinuaciones de decadentistas a lo Lorraine, que publicó en 1911, en varios números de Variedades. Además dió a luz una novela corta "La Ciudad Muerta" y empezó a revelarse cuentista excelente desde 1910. La política lo sugestiona con pasión e inquietud social y lo beneficia temporalmente. Vinculado a lg candidatura presidencial que triunfa en 1912, Valdelomar emprende al año siguiente el viaje a Europa. Asu regres6icomienzala nueva etapa y la definitiva en su vida, aquella que, al decir de César Vallejo, "apunta una nueva época en la literatura peruana". Comienza su colaboración asidua y trascendente en La Prensa de Lima, en secciones que no deja envejecer ni en el titulo ni en la forma. El lector común de entonces busca insistentemente sus "Comentarios" o sus "Palabras", las Crónicas Frágiles", sus "Impresiones", los "Fuegos fatuos", los "Diálogos Máximos" o la sección "Al Margen del Cabie". Su actividad es múltiple. Ejerce el periodismo pero al mismo tiempo revela un escritor de calidad, que colabora en las mejores revistas del continente, que dirige una revista memorable, Colóntda, en 1916, y que empieza publicar libros.

Colónida, que da nombre a la generación que recoge en sus páginas y que tiene por líder a Valdelomar, constituye un momento trascendental en la literatura peruana. "Representó, -ha dicho 
Mariátegui, precisamente uno de sus colaboradores y exégetasuna insurrección contra el academismo y sus oligarquías, su énfasis, su gusto. conservador, su galantería dieciochesca y su melancolía mediocre y ojerosa. No fué un grupo, no fué un cenáculo, no fué una escuela, sino un movimiento, una actitud, un estado de ánimo". Colónida concretó y definió el ideal perseguido y realizado sólo en parte de dos importantes revistas literarias anteriores, editadas por Enrique Bustamante y Ballivián: Contemporáneos, en 1909, y Cultura en 1915.

Puede decirse que en Colónida nace la nueva literatura del Perú. En ella empieza a torcerse el cuello al modernismo, colocada la revista en la encrucijada entre lo viejo y lo nuevo. Acoge todo lo anterior que algo representaba y que debía quedar para la posterioridad. No excluye lo que tiene valor permanente. Pero al mismo tiempo intuye el futuro y promueve y estimula lo que ha de venir, exaltando a los valores que en tiempos venideros han de ganar la fama, pese a la incomprensión de los críticos oficiales. Tal es el caso de José María Eguren, cuyo nombre es proclamado por vez primera como la más auténtica realidad poética de los últimos tiempos. Entre tanto, Valdelomar publica su primer libro La Mariscala (1915) que es la insinuación de una biografía novelada, tal vez poematizada, de una mujer de la historia, doña Francisca Zubiaga esposa del General Agüstín Gamarra, dos veces presidente del Perú. Le sigue otro volumen, El Caballero Carmelo, en 1918, en el que reune bajogel fítulbiya conocido, 'unà coleccción de sus cuentos, con prólogo de Alberto Ulloa y un apéndice crítico. Allí figuran sus cuentos de ambiente costeño, los cuentos yanquis, los cuentos chinos y los cuentos incaicos, en sucesivas secciones. Poco después aparece Belmonte, el trágico (1918), ensayo de una estética futura a través de un arte nuevo.

Probablemente si revisamos nuestra literatura posterior, encontraremos libros mejor escritos pero no libros que signifiquen como los pocos que nos legó Valdelomar en lapso muy breve e intenso, tan grande inquietud ni tan grande reacción contra la estulticia y el desdén generalizado por la actividad artística ni que entrañen tan formidable esfuerzo por desechar lo anecdótico, en pos del alma colectiva nacional, y lo cursi y retórico, en pos de lo selecto y refinado.

Pero su trayectoria de creador habría de ser prematuramente interrumpida por una muerte accidental y absurda, ocurrida en 
Ayacucho, el dos de noviembre de 1919. El caudal de su producción quedó trunco y disperso. Por sobre todo sentimiento de escuela o tendencia literaria, por sobre las influencias europeas que en una época lo embargaron, Valdelomar vió y vivió siempre al $\mathrm{Pe}$ rú su tierra y su hombre.

Concibió y sintió el concepto de patria como una continuidad en el tiempo y una totalidad en el espacio, tuvo el orgullo de ser peruano al par que también, y sin resentimiento alguno, tenía a honra proclamar su origen modesto y su pobreza familiar. Su aristocraticismo era formal y convencional. Era siemple recurso para anonadar a los "burgueses", mas no para engañar al prójimo. Cuantas veces pudo, solía aproximarse al pueblo y dejarse comprender por el pueblo.

$\mathrm{Si}$ en alguna ocasión dijo: "La función del artista, y en este caso del poeta, es descubrir por el sentimiento lo que la naturaleza tiene de eterno y esquivo", había de practicar este prinripio lealmente con respecto a su propia tierra; para él, la naturaleza era la que había vivido y había nutrido sus años infantiles y de adolescencia, la costa y el mar peruanos, y también los Andes y todo su Perú, en fin, sin recurrir a paisajes artificiales o extraños, sin tratar nunca de descastarse.

Es mérito perdurable de Valdelomar no sólo haber multiplicado su actividad periodístice y en general dignificado literariamente el periodismo en todas las formas posibles sino también haber mantenido una alta calidad de selección artística en todos sus escritos y logrado grabar el sentido de lo eterno en la fugacidad de la crónica, lo esencial en medio de la levedad.

Es también mérito notorio haber insurgido contra lo adocenado y lo yerto, rompiendo cánones falsos y fustigando valores sin sustento, y no obstante la exigencia de su gusto estético, poner su arte al servicio de los más, con sentido popular y democrático. Por que Valdelomar supo hacer arte sin melodrama, sin complicación innecesaria, sin retorcimiento alguno, con los medios más sencillos, logrando la calidad selecta sin enrevesamiento.

Puede ser revelador - y merece hacerlo con detenimiento para juzgar el proceso de su creación literaria, insistir en la experiencia viajera de Valdelomar, así como reconstruir el itinerario de un viaje (que fue el único en su vida y que definió su destino literario) por Europa y por América del Norte. Los últimos escritos suyos, un 
tanto desconocidos, que se vienen publicando desde hace poco (1) dan mucha luz sobre ello y podemos avanzar en el desbrozamiento del tópico. Es trascendente su residencia en Roma, en el desempeño de un cargo diplomático, cuyo nombramiento le fue concedido en mayo de 1913, y que desempeñó desde agosto de dicho año hasta febrero de 1914, en que renunció con dignidad ejemplar, al perder el poder el caudillo que lo nombró. Pero no sólo es de interés el punto de destino, Roma, sino también el trayecto, por los estímulos creativos que va recogiendo en las escalas. Son apenas 10 meses de viaje los que vive Valdelomar con una intensidad excepcional. Zarpa del Callao en junio de 1913, hace escala en Panamá (cuando todavía el canal no estaba concluído) y trasborda a otro barco después de visitar Antigua, navega en el Atlántico y desembarca en Nueva York a comienzos de julio. Sus poemas últimamente publicados nos dan fechas y puntos del itinerario pero no hay impresiones de ese trayecto, salvo rápidas referencias en su prólogo a El Alma Encantada. En cambio, va forjando obra de creación literaria. De la breve estancia en Nueva York emergerán poemas y sobre todo la textura interesante de algunos de sus "Cuentos yanquis". La travesía es fructuosa en nuevas imágenes y observación psicológica de gentes racialmente diferentes $\circ$ de usos de vida extraños que llaman a la ironía o a la emoción lírica. Un transatlántico moderno lo traslada de Nueva York a Génova.

El itinerarjoleuropeecin SelinstalaeenoRoma y en los seis meses escasos de vida en la ciudad eterna, su actividad se multiplica. Allí encuentra la disposición espiritual requerida para redactar uno de sus mejores relatos, "El Caballero Carmelo", para dar forma definitiva a sus "Cuentos yanquis"; dirige preciosas cartas a sus amigos y familiares; escribe sus finas "Crónicas de -Roma" que sólo fueron cinco, además del prólogo autobiográfico de su proyectado libro La Aldea Encantada que pensaba editar en España y algunos poemas como "Luna Park" y traduce algunas poesías italianas, entre ellas "Ultima rosa" de Fogazzaro. Se ha dicho equi-

(1) A. Valdelomar, Obra poética, prologada, compilada y anotada por J(avier) C(heesman), Proemio de Luis Alberto Sánchez, Lima, Asociación Peruana por la Libertad de la Cultura, 1958, 127 p.

A. Valdelomar, Cuento y Poesía, prólogo, selección y notas por Augusto Tamayo Vargas, Lima, Patronato del Libro Universitario. Imp. de la Universidad de San Marcos, 1959, 233 p. 
vocadamente que en Italia, Valdelomar se empapó de la influencia de D' Annunzio, cuya obra pudo conocer de cerca, y de toda la literatura que le era afín. Pero lo evidente es que en Roma precisamente se despojó de esa influencia d'annunziana y afirmó su sentido de escritor americano. Así fue en efecto, al revés de lo sucedido con tanto escritor desarraigado. Los escritos de Valdelomar que acusan influjo d'annunziano son de fecha anterior al viaje, como "La ciudad de los Tísicos" o "La ciudad muerta" (de 1910 u 1911) y justamente los relatos de más sentido americano y menos finiseculares que salen de su pluma, se escriben a partir de la estada romana. A punto de dejar el cargo que desempeñaba, a comienzos de 1914, Valdelomar visita Florencia y Milán y producida su renuncia, inicia el regreso por la ruta de Marsella. Encuentra allí a su compatriota Riva Agüero, también afirmando su peruanidad en Europa, en vísperas de componer su famoso ensayo sobre Garcilaso, el Inca. Sigue a París a mediados de marzo de 1914, cuando ya se hace tensa la política europea. Su intención más personal era seguir a España y no lo hizo lamentablemente por escasez de recursos, y por atender a sus familiares dejados en el Perú con quienes se sentía moralmente obligado. Visita París, de paso, pero vive intensamente los días que le dedica. Muestra de su experiencia parisina es la estrofa siguiente:

\section{En París, una noche, una dama, el Destino y mi sudamericana curiosidadonverso" lleváronme hacia la maravilla deslumbrante y sonora de Luna Park}

Allí en París, en Luna-Park, entre la alegría de turistas mediocres encuentra Valdelomar un grupo de cafres salvajes, negros de algún perdido rincón de Africa, llevados para saciar el ansia de exotismo. El poeta se conmueve y siente que aquellos desventurados han podido serlo también sus amados indios o "cholos" peruanos:

Y pienso: pobres salvajes míos ¿qué cosa haceis en Luna-Park? Estas gentes, hermanitos incautos, después de compraros os venderán $y$ os harán el gran daño de quereros en pago civilizar. 
¡Infelices salvajes!, no más bosques ni ríos,

No más valles fecundos, no más asar cabritillos silvestres en las fogatas rojas

ni vencer la furia del brutal elefante, ni del inquieto tigre, ni del león iracundo

¡Os van a civilizar!

El poeta vuelve y se afirma a lo suyo, incrementando su fuerza creadora, en medio de esa experiencia europea. Francia no tuvo el efecto de superfluo deslumbramiento en su alma. Por el contrario se afirmó y perfiló allí su personalidad fulgurante y extraordinaria, al contacto de esa Francia de pre-guerra, despreocupada e incrédula, lánguidamente sensual y frívola, ávida lectora de Maupassant y de Barrés, de Maeterlinck y de Lorraine,- como antes y después en la eterna Italia y sobre todo en esa Roma "triste y melancólica" afirmada en un pasado de ruinas y en las explosiones materialistas del futurismo de Marinetti- y adquirió un enfocamiento realista del arte y una aproximación constructiva a la naturaleza americana, viviente en sus paisajes de la costa peruana y en el alma de sus habitantes nativos, móviles de toda su creación literaria posterior. Fenómeno semejante iba a operarse once años después, desde 1920, en otro gran escritor peruano, José Carlos Mariátegui, quien emerge con un sentido positivo $y$ realista de su viaje y estada en el Viejo MundC, abandonandolíngeniosos pero vacuos idealismos dejuventud.ccinelli Converso»

\section{Valdelomar en Nueva York}

Vale la pena detenerse en su breve experiencia norteamericana. Valdelomar arribó a Nueva York a fines de junio de 1913 Y reside allí varias semanas en espera del barco de conexión para Europa. Un escrito suyo recientemente revelado, el prólogo a un libro que nunca se publicó, El Alma Encantada, recoge impresiones muy vivas de la gran ciudad de los rascacielos:

"Vi casas tan altas que se perdían en la celeste vaguedad. Por el aire curvábase la serpiente de un ferrocarril; en la tierra, enormes bocas abiertas atraían y se tragaban a infinidad de gente que por otras bocas salían, como por encanto de una extraña digestión. Un lenguaje de jotas y de kaes, mezclado con negras nubes 
de humo, vomitado por invisibles chimeneas, me robaba el oxígeno. En amplias calles atropellábanse millones de seres apurados, y aquel río humano, interminable, sonoro, obsesionante y dantes$\mathrm{co}$, en medio de máquinas, sobre puentes, bajo alambres, hundiéndose ora en la tierra, elevándose luego en el espacio, rodó, rodó todo el día, fatigante y mortal, hasta que llegó el luminoso prodigio de la noche.

¡Oh, mis nervios! ¡Oh aquel mar de fuego, en medio del cual como náufragos, se debatían funambulescamente mis semejantes! Cruzaban como flechas fugaces y veloces, los autos, las motos, los tranways, los taxis, los ómnibus, las mujeres y los hombres. Tales mariposas de luz. En los enormes muros la luz hacía prodigios fantásticos. Veíanse en el cielo, sobre la ciudad o en medio de ella, en luces, caprichosas danzantes, hombres que boxeaban, botellas estallando en precioso licor, y letras, letras grandes, chicas, gruesas, delgados, redondas, góticas, griegas, en luces rojas, azuies, verdes, amarillas, moradas, lilas, violáceas y rosas; y zapatos, caballos, mujeres, botellas, violines, fonógrafos, naipes, dientes, corsés, estómagos, monturas, cruces, sombreros, maletas y cigarrillos. Todo en luz! Todo en luz! Todo en luz! ...

Un joven amigo, que nos acompañaba, llevóme de la mano como Virgilio al Dante, en medio de ese infierno luminoso que $\mathrm{mi}$ imaginación jamás sônará y me dijo en la confluencia de dos de esos ríos desbordantes, señalando con el brazo extendido:

- Esto, esto es Broadway - y girando un poco agregó- y esto de acá es la Quinta Avenida. Estamos pues en el cruce. Este es el Centro del Mundo.

Palpábame yo para estar seguro de que aquello era real, mientras pasaba la humanidad como un río que arrastra sus piedras, y de repente aquel mundo incontenible que rodaba, que parecía incapaz de detenerse ante nada, avasallador, monstruoso, atilino, quedóse inmóvil como congelado en un movimiento sorpreso.

- Qué pasa, qué pasa? -interrogué, preveyendo no sé qué extrañas catástrofes.

¿Qué poderosa fuerza extraterrestre había podido inmovilizar a aquella humanidad hormigueante?

- Mira - me respondió mi amigo, señalándome a un hombre colosal, que se erguía en el centro matemático, con una pequeña vara en la mano- mira, aquí no es como allá... 
El hombre que había levantado la varita era el policeman. Bajóla luego serenamente y el mundo siguió su curso normal y cotidiano... Tuve una sensación de tornillo".

Esta es la sensación directa y vivida que contrasta con algunos rastros de impresiones que se recogen en sus obras, de la etapa anterior o posterior a su estada en Nueva York. Hay impresiones imaginarias previas a su encuentro con la gran ciudad, ficticias, intelectuales, como aquella de "El beso de Evans" (publicado en Balnearios, Barranco, 13 de agosto de 1911 y corregido después del viaje para la edición en volumen de 1918): "Lady Alice piensa en América. Fantásticamente hace surgir del nebuloso horizonte el continente de los hombres rudos... Casas inmensas. En estatua colosal, una mujer extiende el brazo, coronada, y señala el camino entre el océano agitado: Nueva York".

Exactamente como en el prólogo recientemente publicado: "vi casas tan altas que se perdían en la celeste vaguedad". Pero aparte de esa impresión que fue ficticia, Valdelomar recoge toda la sensación del ambiente cosmopolita de la gran ciudad en sus llamados "Cuentos yanquis". Xammar ha hecho referencia al "criterio deportivo" que norma estos cuentos y a su condición de "capítulos episódicos en el destino de su obra", ... y que..." son irónicos y revelan ingenio, despreocupación, intrascendencia".

No participo enotodo de estas afirmaciones un tanto desdeñosas. Como veremos en seguida, esos cuentos de ambiente norteamericano adquieren una especial significación como relatos de honda elaboración y en cuanto constituyen documentos de captación de otras realidades vividas, a la inversa de lo que implican por ejemplo, sus "cuentos chinos", pura expresión de fantasía decadentista y exótica "con finalidad política, y que desmerecen, más que acreditan, el balance de la obra". (Xammar).

Llegado al lugar de su destino, Roma, Valdelomar escribe con la experiencia tenida en el puerto de Nueva York, y fechado en julio de 1913, su segundo cuento "yanqui" titulado "Tres senas; dos ases" (publicado en La Prensa, Lima, julio de 1915). El primero había sido "El suicidio de Richard Tennyson", publicado a comienzos de 1910 en Varledades (números 100 y 101, Lima 29 de enero y 5 de febrero de 1910, págs. 145-146 y 183-186, dedicado a Manuel Beingolea), y no mencionado en ninguna de sus bibliografías. Este cuento tiene además la característica de ser su primer escrito en prosa -y su primer cuento- aparecido en revistas, ya que hasta 
entonces (o sea hasta 1909) sólo había publicado poemas o ilustrado periódicos diversos con sus caricaturas. Este cuento "yanqui" fue corregido y ampliado en Roma, valiéndose ya de su reciente experiencia neoyorquina, y rebautizado con el título "El Círculo de la Muerte", nombre con el cual se publicó nuevamente el año subsiguiente en Colónida ( No 2, Lima, $1^{\circ}$ de febrero de 1916) y se incorporó después dentro de la recopilación de su obra cuentística en el volumen El Caballero Carmelo, Lima, Imp. de la Penitenciaría, 1918). Así pues, de sus cuentos con ambiente foráneo, aunque anteriores al viaje, como "El beso de Evans" (de 1911) y "El suicidio de Richard Tennyson" (de 1911) Valdelomar modificó muchas referencias ambientales, adicionándoles nuevos elementos de paisaje captados en el viaje o corrigiendo inexactitudes. Resultaría muy ilustrativo y provechoso en la estimativa de Valdelomar, estudiar las variantes introducidas.

En el otro cuento yanqui, "Tres senas; dos ases" (aparecido en La Prensa, Lima, julio 7 de 1915)/y que corresponde a la etapa posterior al viaje, está descrito el ambiente con delicada fidelidad: "Invité a almorzar a Irving para el día siguiente, en Coney Island. Iríamos en auto. Nos despedimos. En efecto, a la hora precisa, el auto de Irving se detenía en el Wotham Hotel, y juntos nos dirigimos hacia Coney Island. Atravesamos las avenidas congestionadas, los edificios colosales huían a nuestro paso, y por fin, pasado el puente de Brocklyn, entramos en aquella maravillosa avenida de abetos que sombrean la asfaltada carretera que conduce a la playa infantil de Coney Island. Allí elegimos un hotel que da al mar, y en una especie de recodo conversamos largamente..."

Los apuntes descriptivos no son frecuentes, pero sí ajustados en presentar lo particular del medio en que se desenvuelve la narración. Sin embargo, parece preocuparlo más el lograr la caracterización típica de los personajes: los dos amigos y la amante de uno de ellos, perfilados con maestría de cuentista, logrados con acierto en sus actitudes, en sus reacciones y en su mentalidad típica de norteamericanos.

Vividas o no vividas, las impresiones norteamericanas de Valdelomar resultan justas y exactas, al menos para su momento. Con ligeros recortes aún hoy lo serían también. Enfoca desde luego al norteamericano común, ho al hombre selecto o de "elite". Para él, el yanqui es un individuo que persigue siempre el enriquecimiento por medios inverosímiles, sin traicionar su practicismo innato. 
Demuestra siempre su eficiencia en sacar partido material de los más absurdos planes y existe en él cierto estoicismo y frialdad para afrontar tranquilamente la muerte o para llevar adelante su decisión de convertir en bienes económicos y tangibles elementos que pertenecen al mundo espiritual.

Le sirven de base para su creación imaginativa algunos factores estadísticos bastante realistas y verdaderos: el alto porcentaje de los suicidios, el desarrollo numérico de los seguros de vida, la afluencia de grandes multitudes a los espectáculos, el auge multitudinario del sensacionalismo, la ausencia de emotividad para afrontar los problemas de la vida y la ingenuiáad en las relaciones de los hombres.

Si comparamos la concepción norteamericana de Valdelocar con la de Juan Manuel Polar, el celebrado autor de "Don Quijote en Yanquilandia", podemos concluir que el primero cala en lo fundamental mientras el segundo utiliza un método simplista de mera exposición imaginaria y/creacionista, contraria a todo verismo. Valdelomar no ha trastocado la realidad viviente del mundo norteamericano, y tanto su concepto realista como la insinuante $\mathrm{y}$ exótica realidad que capta, muy siglo XX, podría decirse que se encuentran actualmente vigentes. Sin duda, el cuadro de Polar responde a un concepto ya caduco en América Latina de lo que son sus vecinós del nortel por lo-general prendido a la imagen idealista y errada de Rodó. Sólo habria que reprochar a Valdelomar su insistencia, dilgo maniática, 'en 'vincular siempre su escenario yanqui a las situaciones macabras y a la temática monótona del suicidio especulativo. Todo ello sin desmerecer desde luego su alta calidad literaria.

Como alcance a dos recientes publicaciones que ofrecen nueva luz sobre la vida y la obra de Valdelomar y compilan algunos textos suyos por primera vez revelados y recogidos en volumen (2) damos publicidad a un conjunto de escritos en prosa del mismo autor producidos entre 1911 y 1913, en época anterior o coetánea con su única experiencia de viaje al extranjero (Estados Unidos y Euro$p a$ ) entre agosto de 1913 y marzo de 1914. Ellos son "La ciudad

(2) Los textos recientes son los mencionados en la nota anterior. 
muerta", novela corta, de título e inspiración d'annunzianos, publicada en Ilustración Peruana, números 80 y siguientes (Lima, 12, 19 y 26 de abril y 3 y 17 de mayo de 1911) y las cinco "Crónicas de Roma", enviadas como correspondencia de viaje desde la Ciudad Eterna al diario La Nación de Lima, (que las publicó en sus números del 21 de noviembre y 23 de diciembre de 1913 y 21, 24 y 30 de enero de 1914). Aunque de género distinto y de actitud diferente, corresponden a la misma etapa de la transformación espiritual de Valdelomar. Mientras en "La Ciudad Muerta", novela corta, se anota inevitable y notoria influencia foránea, en las crónicas romanas puede advertirse ya el cambio favorable que el impacto del viaje ejercerá en un temperamento exquisito como el de Valdelomar, esto es, que la realidad europea sirve al autor para afirmar su sentido americano y una original concepción literaria, despojada en la propia Italia, del influjo arrollador del autor de Las vírgenes de las Rocas y en la propia Francia, de la sugestión que sobre él ejercía el decadentismo de Lorraine y Huysman. Esas crónicas muestran un cercano parentesco con algunas de las posteriores crónicas de viaje de José Carlos Mariátegui y con los artículos y breves ensayos en prosa de José María Eguren que hace poco he publicado ( 3 ).

De otro lado, las recientes publicaciones a que he aludido y la presente, demuestran un hecho muy singular: que Valdelomar suele viajar de dos maneras, o sea en forma ficticia, en alas de la imaginación, o en qofma real, incorporandor sü propias y vividas experiencias del viaje cierto. Al parecer "La Ciudad Muerta" sería el producto de un viaje a Río de Janeiro, que nunca hizo y donde nunca estuvo. Otro cuento suyo "El beso de Evans", ambientado en Marsella y París, (publicado en Balnearios el 13 de agosto de 1911) se escribió mucho antes de su estada en Francia en donde estuvo precisamente dos años más tarde, en Marsella y París y por dos veces (julio o agosto de 1913 y febrero de 1914).

Por lo tanto, participa de la misma característica de relato ficticio que tiene "La ciudad muerta", aunque porteriormente sufrió variantes provenientes del viaje real.

En Brasil nunca estuvo Valdelomar, y por la época de com-

(3) José María Eguren, Motivos estéticos, recopilación, prólogo y notas por Estuardo Núñez, Lima, Patronato del Libro Universitario. Imp. de la Universidad de San Marcos, 1959, 228 p. 
posición de "La Ciudad Muerta" (febrero de 1911), el autor, universitario de San Marcos, se dedicaba a la campaña política de su caudillo predilecto, el futuro Presidente del Perú don Guillermo E. Billinghurst. Este le dió desde el poder, la oportunidad de viajar como diplomático, a Europa, mas por la vía de Nevs York, entre mediados de 1913 y comienzos de 1914. Si bien Río de Janeiro no estuvo en su itinerario, el destino io llevó realmente a Norteamérica y a Europa, en donde se opera con las nuevas vivencias y el impacto del conocimiento de medios extraños, una honda transformación de su sensibilidad, la liberación de influjos juveniles y el descubrimiento de su auténtico destino de creador americano.

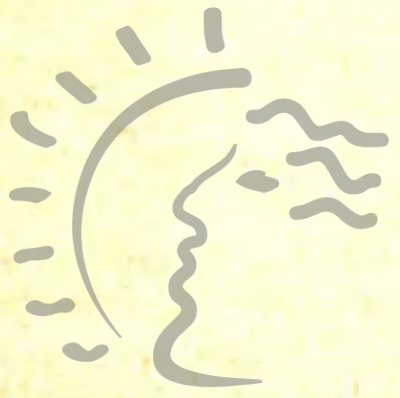

Biblioteca de Letras "Jorge Puccinelli Converso" 